\title{
Assessing socioeconomic effects on different sized populations: To weight or not to weight?
}

\author{
N Frohlich, K C Carriere, L Potvin, C Black
}

\begin{abstract}
Objective-Researchers in health care often use ecological data from population aggregates of different sizes. This paper deals with a fundamental methodological issue relating to the use of such data. This study investigates the question of whether, in doing analyses involving different areas, the estimating equations should be weighted by the populations of those areas. It is argued that the correct answer to that question turns on some deep epistemological issues that have been little considered in the public health literature. Design-To illustrate the issue, an example is presented that estimates entitlements to primary physician visits in Manitoba, Canada based on age/gender and socioeconomic status using both population weighted and unweighted regression analyses.
\end{abstract}

Setting and subjects-The entire population of the province furnish the data. Primary care visits to physicians based on administrative data, demographics and a measure of socioeconomic status (SERI), based on census data, constitute the measures.

Results-Significant differences between weighted and unweighted analyses are shown to emerge, with the weighted analyses biasing entitlements towards the more populous and advantaged population.

Conclusions-The authors endorse the position that, in certain problems, data analyses involving population aggregates unweighted by population size are more appropriate and normatively justifiable than are analyses weighted by population. In particular, when the aggregated units make sense, theoretically, as units, it is more appropriate to carry out the analyses without weighting by the size of the units. Unweighted analyses yield more valid estimations.

(F Epidemiol Community Health 2001;55:913-920)

GRIS-Université de Montréal

L Potvin

Correspondence to: Professor Frohlich, Department of Business Administration, I.H. Asper School of Business, University of Manitoba, Winnipeg, Manitoba, Canada R3T 5V4

(Norman_Frohlich@

Umanitoba.ca)

Accepted for publication 30 May 2001
We argue that the correct answer to that question turns on some deep epistemological issues that have been little considered in the public health literature. We endorse the position that data analyses unweighted by population size are often more appropriate and normatively justifiable than unweighted analyses. In particular, when the units of analysis are aggregated individuals whose aggregations make sense as units, it is more appropriate to perform unweighted analyses. Unweighted analyses can yield less biased estimations of the aggregate level parameters. Alternatively, weighting might provide approximate solutions if one were interested in making inferences at the individual level from the aggregated data.

We use an example from Manitoba, Canada to demonstrate the effects of the methodological decision of weighting areas by their populations and show how that decision can lead to very different estimations of utilisation and entitlement.

A problem implicit in the traditional approach to ecological analyses

Rothman ${ }^{2}$ defines ecological studies as those using groups of people or areas as observation units rather than individuals. His recommendation is to weight each area or group by the size of the population because "the amount of information in each observational unit will differ."(page 304). ${ }^{2}$ This prescription has been followed by some researchers who have linked resource allocation to the socioeconomic and demographic characteristics of the population. ${ }^{3}$ By contrast, a number of empirical studies that address the role of social cohesion and social capital on health ${ }^{4}$ are unweigthed correlational analyses of aggregate data (for example Kennedy et $a l^{\bar{l}}$ andKaplan $e t a l^{6}$ )

There are a few reasons why weighting may have appealed to analysts. ${ }^{7-9}$ One is the traditional argument that risk factors are assumed to operate at the individual level and so the number of individuals with particular characteristics is assumed to be a relevant factor. Another reason is that many models are based on samples from larger populations and it is important that the model reflects the relevant characteristics of the underlying distribution of the larger population. This is particularly important when sampling is not proportional to the size of areas involved and the aim of the analysis is to estimate an "overall" mean rather than to estimate means for each group or area. Despite the substantive importance of this analytic choice, relatively little attention has been paid to the theoretical justification for this way of proceeding.

Implicit in the first argument is the notion that the question to be addressed is meaningful 
only at the level of the individual. The assumption is that were data available at the individual level the analysis would be carried out at that level: the resort to aggregate measures is only a function of the unavailability of individual data. There is a concern that the inferences made from aggregate level data, when applied to individual level phenomena, are vulnerable to the cross level biases that occur when confounding or effect modification is heterogeneous across analytical units. ${ }^{10}$ Such cross level biases result in a failure of the ecological effect to reflect the biological effect at the individual level and has been labelled the "ecological fallacy". ${ }^{11}$ There exist several means by which one can identify the presence of cross level bias and correct for the ecological fallacy. ${ }^{12}$

On the other hand, critics have emerged who have begun to question the appropriateness of focusing solely on variables and phenomena at the individual level for an understanding of health and health outcomes. For example, Shy ${ }^{13}$ argues that epidemiology has become a biomedical discipline focused on the distribution and determinants of disease in groups of individuals and has disregarded the ecology of human health. Some have introduced aggregate level concepts such as collective lifestyle to render the idea that health and its determinants are shaped by collective attributes. ${ }^{14}$ Others have identified the concept of an "individualistic fallacy". This occurs when population patterns of outcomes are erroneously presumed to be explicable only by individual level characteristics. $^{15}$

Another argument for the aptness of weighting by population turns on representativeness. That argument is applicable if the analysis is based on a sample from a larger population and the objective is primarily to estimate the overall population. When the analysis is based on an entire population, that argument loses much of its force. That caveat is particularly germane if the population is broken into areas that are believed to have unique area level characteristics that can affect the status of individuals and there is no reason to believe that those effects are a direct function of size. In those cases, an analysis unweighted by population would be more appropriate to measure the impact of those area level variables.

One possible means of dealing with these problems is the use of hierarchical modelling that separates individual and area effects. ${ }^{16}$ However, weighting versus unweighting remains an issue in that estimating procedure. Moreover, that form of modelling may not be appropriate for analyses that attempt to identify only area level effects. For example, Ross et $a l^{17}$ have recently produced a univariate analysis of the relation between income inequality and mortality in Canada and the United States based on a state and province level analysis. Their analysis evidences how the decision to weight by population can affect the inference. In private correspondence Ross has indicated that, in Canada, the slope of the estimating equation between income inequality and mortality on a population weighted basis is $-2447(\mathrm{p}=0.22)$ while on an unweighted basis it is $+2444,(p=0.09)$, based on 10 area level data.

When one is dealing with very large populations, (for example, over one million people in Manitoba) the sheer size of the population, even when the data are available, makes it difficult or inappropriate, to proceed at the individual level of analysis. Frequently, the data may be skewed. Moreover, the distribution over the variables to be considered may be sparse with the attendant problem of high variability. And finally, conclusions about the phenomena in question may be more relevant and interesting at some area (or any other relevant grouping) level of analysis. These considerations call for an approach that aggregates the individuals into meaningful units of analysis. This in turn raises the epistemological question of the existence and definition of the entities made up of those aggregated individuals as well as the methodological question of assessing their characteristics.

The epistemological question about "when is an aggregate of persons an entity?"(page $16)^{18}$ is indeed a question of setting boundaries in such a way that they allow reliable classifications of any individual as either included in or excluded from the entity of interest. Campbell ${ }^{18}$ has demonstrated that boundaries for mineral, biological or social entities do not exist as objective facts: they are constructed and inferred from a series of perceptive clues and subject to diagnostic procedures to confirm the existence of a meaningful entity. The degree of a priori reality of a given entity stems from the multiplicity of diagnostic procedures that can be utilised and the convergence of their results. Such a perspective emphasises the fact that entities may be modelled differently according to the question being addressed and that the robustness of any modelling depends on the underlying theory. ${ }^{19}$

Once groups of individuals have been identified as meaningful entities, testing for relations among variables can be performed using either individual aggregated measures or environmental indicators. ${ }^{20}$ Aggregated individual measures are those most widely used. They are averaged or summed up across individuals to reflect a collective attribute such as average income, prevalence, or mortality rate. Environmental indicators result from the observation of features emerging from the aggregation of individuals. These macro-properties such as the number of hospital beds per population unit, do not have corresponding meaning at the individual level. ${ }^{21}$ The use of environmental indicators orients the analysis and the inference to the aggregated level. Aggregated individual measures, on the other hand, can in many cases, be used both for individual level and aggregate level inference. In performing an analysis, then, one must consider the arguments for and against using the population size of the area as a weight variable in a population based analysis. The immediate effect of weighting area level observations by their populations is simple to describe: areas with larger populations have a greater impact in the estimation of 
the model. Consider, for example, a suggestion made by Noralou Roos. Suppose the World Health Organisation were attempting to determine the link between the levels of industrialisation of nations and their health statuses. Suppose they were to use a population weighted model. China and India both have huge populations and although they are both at the lower end of the development scale, they would largely determine the result. The variation between those two countries would determine much of the nature of the relation even though it would be based on a very small spread in the independent variable (level of industrialisation). The effects of economic development and industrialisation at the higher end of the scale, represented in the European and North American countries (of smaller populations) would be largely masked as would the contribution of much of Africa and South America. Weighting by population would underestimate the effects of the smaller population countries and overestimate those of the larger countries. On the other hand an unweighted analysis runs the risk of having many small countries play a disproportionate part in determining the relation.

How does this example lead one to argue for an unweighted analysis as more appropriate? Firstly, theory and evidence indicate that the areas under consideration can be treated as entities: they have one or more characteristics that have effects on an outcome that are meaningful at the population level. Secondly, the variables of interest are not distributed in the same way in the less populated areas as they are in the more populated areas. It should be noted, that these conditions preclude the aggregation of smaller areas into larger areas to balance the sizes of the units under analysis, and thereby to finesse the weighting problem. And finally, there is a correlation between the variables of interest and the size of the population that is not deemed to be of theoretical importance. Taken together, these characteristics lead one to conclude that an unweighted analysis more accurately reflects the underlying relation between the explanatory variable and the outcome. A population weighted analysis overrepresents the larger areas and underrepresents the smaller areas and hence biases the estimate.

\section{Methods}

We present an example that uses socioeconomic and demographic data to derive a measure of entitlement to physician services. Data from the entire population of the Province of Manitoba were aggregated at the level of physician service area (PSAs). These areas were geographically contiguous towns or areas within municipalities that shared the bulk of their visits to a given concentration of physicians. ${ }^{1}$ These data were used to identify the relation between demographic and socioeconomic indicators (which were treated as proxies for need for health services) and utilisation of primary care visits to physicians.

This example is presented primarily for purposes of illustrating the methodological point we argue. However, it is substantively important in its own right because, increasingly, providers of comprehensive health care have begun to realise that the socioeconomic and demographic characteristics of their client populations can have a profound effect on the level of services demanded (and, possibly, warranted). In Canada, where the provinces fund these services centrally, there has been a move towards the establishment of regional health authorities ${ }^{132-24}$ who service diverse populations. A similar challenge faces HMOs in the United States operating multiple centres in areas with disparate populations.

The Province of Manitoba has recently established provisions for 12 regional health authorities. One of the first policy challenges has been determining the appropriate levels of regional funding. Central to that concern is the question of exactly how various indicators should enter into the determination of funding entitlements. Frohlich and Carriere ${ }^{24}$ conducted analyses to aid the development of needs based formulas for funding physician services in the province. Their analysis used socioeconomic and demographic indicators to estimate a reasonable basis for allocating resources. It is well established that need and utilisation patterns in the population vary as an interactive function of age and gender. Consequently, it is standard practice, in comparing different population aggregates, to adjust for age and gender differences in populations.

Another factor, widely recognised as affecting health status, and hence probably need for services, is the socioeconomic status of the population. An index of socioeconomic status has been developed for the Manitoba population. The Socio-Economic Risk Index (SERI) is based on census data, which reflects the relation between the socioeconomic status of the population and health status. ${ }^{25}{ }^{26}$ Using data from 282 municipalities, a broad swath of socioeconomic variables from the 1986 census, were modelled against five indicators of poor health and lifestyle, aggregated into an index. Six census variables were found to be closely related to this index and to explain a significant amount of the variance (59\%). Three of these were positively related to poor health: the percentage of the labour force unemployed: ages 15 to 24 , the percentage unemployed between 45 and 54, and the percentage of single parent female households. Three were negatively related: the percentage of the population between the ages of 25 and 34 having graduated high school, the percentage of females participating in the labour force and the average dwelling value. The predicted health statuses from the estimated equation were used to construct a standardised index: the SERI with a mean of 0 and a standard deviation of 1 . The resulting index was shown to be strongly related to a number of other measures of health, such as premature mortality. ${ }^{2526}$ In the analysis of primary care visit entitlement, that index was used as a measure of socioeconomic status. ${ }^{1}$

The analysis was initiated on the premise that a first cut at entitlement to physician visits 
might be calculated by fitting age, gender and socioeconomic status (SERI) in a model to estimate average existing patterns of visits across PSAs. The calculated averages could then furnish the basis for determining an average entitlement for each area based on its age/ gender mix and socioeconomic status.

The rationale for this as a first step is the premise that the universally funded medical system is somewhat, but imperfectly, responsive to the underlying health status of the population in the province. An estimate of average visits adjusted for age, gender, and socioeconomic status could serve as the basis for a first cut at estimating average entitlements to primary care visits for each area. For example, variations in the supply of physicians might well affect actual visit rates. Hence, areas with low levels of supply would probably show up as having visit rates that were lower than their estimated entitlements (given their age, gender, and SERI composition).

The model was constructed by identifying all ambulatory visits in the province outside of hospitals in 1993/94 at the individual level. Starting at the municipality level (259 municipalities) the province was divided into 58 PSAs. These areas were defined in terms of where individuals were getting the bulk of their primary care visits. The defining characteristic was a concentration of population and an associated set of physicians (usually no fewer than five) serving that population.

Using per capita visits as the dependent variable, a multiple linear model was constructed. The population in each PSA was divided into 21 age by gender categories: ages $0-1,2-4$, $5-9,10-14, \ldots ., 90-94$, and $95+$ years old by male or female. The outcome to be analysed was the actual rate of ambulatory visits to physicians. Visits to nursing stations were included. This reduces, somewhat, the issue of low supply of physicians in remote areas.

Thus each PSA was represented by 42 data points. Each represented an age/gender category and its associated average primary care visit level. In all, this comprised a total of 2436 observations. The areas varied in population size from 1020 to 120250 and the age and gender groups varied in size from 1 to 6554 .

The equation to be estimated was:

average visits per capita $=f($ age $\mid$ gender $\mid$ SERI $)$

where "|" indicates the model incorporates all two and three way interaction effects.

That multiple linear analysis is really nothing more than a kind of averaging of utilisation patterns of ambulatory visits according to the areas' age and gender groupings and SERI scores. The coefficient of each of the input variables in the model represents the impact of that characteristic on utilisation. It gives an estimate of the entitlement to visits for a member that category. Three characteristics (age, gender, and SERI of the PSA) and their interactions determine how many visits, on average, any individual is entitled to, given the prevailing pattern of visits in the province. The overall goodness of fit of the model shows the extent to which the areas in the province are receiving
KEY POINTS

- The decision to weight an estimating equation by population can have both substantive and normative implications.

- In estimating equations with individual and area level effects attention must be paid to the issue of weighting by population.

- When population aggregates make theoretical sense weighting by population in an estimating equation may bias estimates.

- When one is interested in ecological relations there is no need to weight estimating equations by population size.

- Ecological analysis on aggregated units may provide useful information when the aggregated units have sociological meaning.

average levels of ambulatory visits in terms of their age/gender/SERI characteristics. The entitlement of an individual would be determined by the estimating equation's coefficients. ${ }^{\star}$ One could use the individuals' entitlements to calculate what the average expected ambulatory visit level would be for each area based solely on the age/gender/SERI characteristics of the individuals in that area.

This descriptive model could be used prescriptively. Each area's relative entitlement would be defined by the mix of ages and genders in its population and their socioeconomic status as measured by the SERI. An area's entitlement to visits would be the sum of the average visit rates in each age/gender category, suitably modified by the SERI factors, multiplied by the population size in that category. This entitlement is a sort of smoothing out - giving each area an expected allocation on the basis of its population's age/gender/SERI distribution based on actual utilisation patterns.

The question of interest to us in this modelling exercise is whether to weight the estimating equation by the populations of the PSAs. Recall that each data point represents an age/gender category in a PSA. The actual number of individuals in any category in an area is the size of the population stratum in that area. One possibility is to perform a population weighted analysis taking into account the different sizes of the areas. That would be consistent with much current practice. ${ }^{3}$ Proceeding in that way, each data point (age/gender stratum in an area) would be weighted by the population in that stratum in that area. That would give weight to an area's population in determining an average utilisation pattern. Hence, the patterns in more populous areas would play a greater part in defining an average pattern than would the patterns of more sparsely populated areas. The resulting "average" pattern would

* For example, the entitlement of a 4 year old girl from an area with a SERI of 1 would be calculated using the coefficients of the variables and their cross terms as follows:

$\begin{array}{llllllll}\text { Constant } & \text { Age } 4 & \text { Female } & \text { Age } 4 \times \text { Female } & \text { SERI } & \text { Age } 4 \times \text { SERI } & \text { Age } 4 \times \text { Female } \times \text { SERI }=\text { Visits } \\ 8.5 & -4.0 & 0.7 & +0.5 & +0.8 \times(1) & -0.3 & -0.1 & =5.0\end{array}$ 


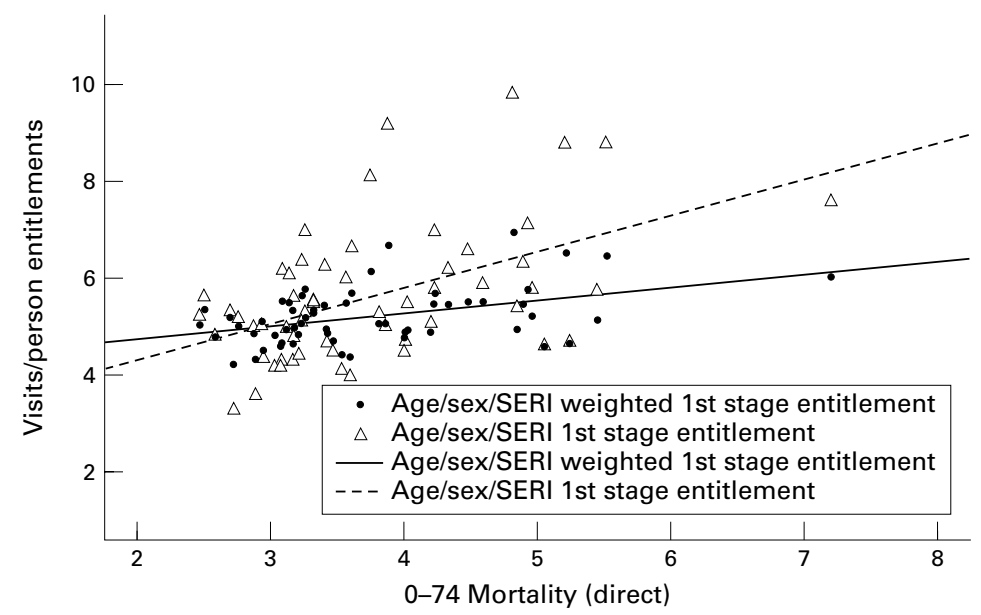

Figure 1 Visits/person entitlements for 1993/4.

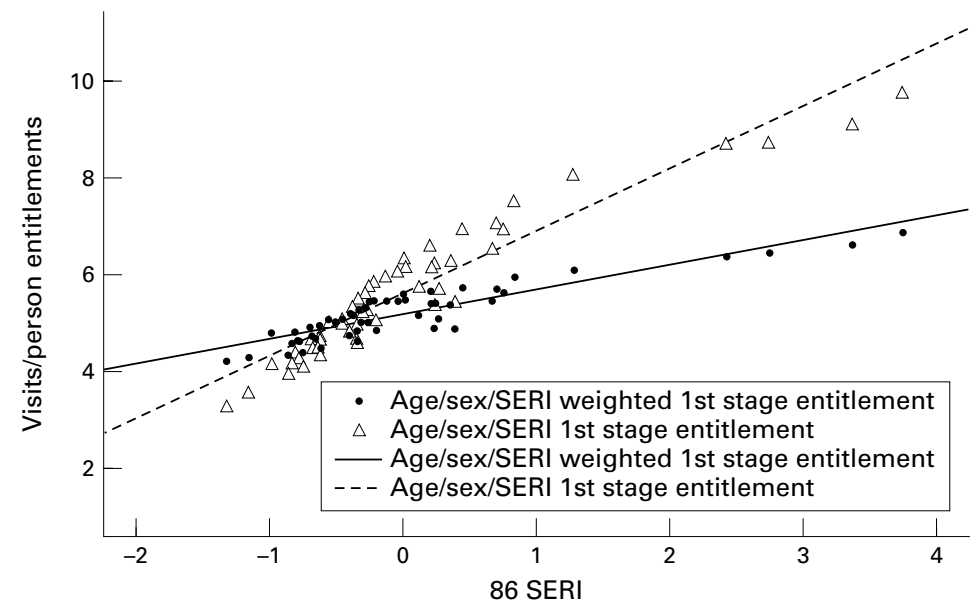

Figure 2 Visits/person entitlements for 1993/4.

reflect utilisation patterns of large population areas more than it would those of smaller areas.

Weighting by population in this way would have particularly pronounced effects on the results in Manitoba because of its distribution of population. In addition to having one diverse city (Winnipeg) consisting of roughly two thirds of the province's population, Manitoba has a number of small, remote, relatively poor northern communities as well as a diversity of farming communities of varying wealth. The range in population size of the PSAs is rather dramatic: from 1020 to 120 250. Hence, doing a population weighted analysis would allow very little influence to the smallest areas.

To complicate matters, in general, the smaller the area the worse off it is (there is a negative Pearson correlation coefficient of -0.320 between population size of the area and the SERI). As usage patterns across the age/gender strata are known to vary as a function of socioeconomic status, a population weighted average could underestimate the entitlement of smaller areas, representing, as it would, the prevailing pattern of delivery in the larger, wealthier, areas. As SERI, the socioeconomic surrogate for need, is correlated with the population size of areas there might be substantial differences in estimated relation from the population weighted versus unweighted analysis.

Alternatively, one could treat each age/ gender/municipality aggregate as an unweighted unit of analysis. * That would eliminate some of the difficulties identified above, but it would give the smallest northern PSA in the province the same impact in the estimation as the largest Winnipeg PSA.

\section{Results}

Figure 1 shows the different effects of population weighted and unweighted analyses. The figure contain two sets of 54 data points (each point corresponding to the PSAs per capita entitlement according to their age/gender /SERI characteristics calculated, as described above ). In figure 1 the entitlements are plotted against the directly adjusted premature mortality rates for individuals between the ages of 0 and 74 years of age (a measure of poor health status and hence indirectly of need for health services).

The estimated slopes of the two lines are very different. The lines in the unweighted analysis (through the triangles) shows a much steeper slope that in the weighted analysis (through the dots). The estimated slopes are 0.643 and 0.257 respectively. The unweighted analysis produces a stronger relation between entitlement and premature mortality than does the weighted analysis.

A complementary look at the differential effect of the two models can be obtained by plotting entitlements against the SERI. Figure 2 shows the relation between the SERI scores of areas and entitlements using weighted and unweighted analyses. Again the unweighted regression line is much steeper than the weighted line.

The differences in allocations under the alternative weighting systems are quite dramatic. Table $1^{1}$ shows the different allocations to the Winnipeg and Northern (remote and poor) regions of the province under the two treatments, along with their observed crude visit rates/per capita, their SERI scores and directly adjusted premature mortality rates. PSAs are listed in order of decreasing SERI in each of the two blocs-that is, in order of decreasing socioeconomic risk.

From the table it is clear how the population weighted analysis allocates more per capita visits to the larger and better off Winnipeg PSAs (in terms of SERI and premature mortality) than does the unweighted analysis. The three relatively poor Winnipeg PSAs do worse under the weighted allocations than under the unweighted allocations. The same is

* There are other ways in which population size could be entered into the analysis. One could conduct a variance weighted analysis. We also did that, but the analysis lead to similar conclusions and so is not reported here. Alternatively, population size in itself could be considered an independent variable which either directly, or indirectly, affects the outcome variable. So, for example, if physician supply were expected to be greater or transportation costs lower, in areas of high population, then utilisation rates might be dependent on the size of the area. 
Table 1 Allocations of ambulatory visits per capita population weighted and unweighted analyses compared

\begin{tabular}{|c|c|c|c|c|c|}
\hline \multirow[b]{2}{*}{ Winnipeg PSAs } & \multicolumn{5}{|l|}{ Winnipeg } \\
\hline & $\begin{array}{l}\text { Population } \\
\text { weighted per } \\
\text { capita allocation }\end{array}$ & $\begin{array}{l}\text { Population } \\
\text { unweighted per } \\
\text { capita allocation }\end{array}$ & $\begin{array}{l}\text { Observed } \\
\text { crude } \\
\text { visits/capita }\end{array}$ & $\begin{array}{l}\text { Premature } \\
\text { mortality } \\
(0-74 y)\end{array}$ & $\begin{array}{l}\text { SERI } \\
\text { scores }\end{array}$ \\
\hline Winnipeg Inner Core & 5.973 & 7.552 & 6.25 & 7.206 & 0.855 \\
\hline Winnipeg Outer Core & 5.417 & 6.164 & 5.44 & 4.344 & 0.225 \\
\hline Winnipeg Old St Bon & 5.475 & 5.849 & 5.97 & 4.600 & -0.203 \\
\hline Winnipeg NE & 4.643 & 4.281 & 4.69 & 3.100 & -0.774 \\
\hline Winnipeg W & 4.825 & 4.406 & 5.20 & 3.225 & -0.795 \\
\hline Winnipeg NW & 4.574 & 4.165 & 5.06 & 3.093 & -0.823 \\
\hline Winnipeg S Central & 4.805 & 4.152 & 5.41 & 3.050 & -0.970 \\
\hline Winnipeg SE & 4.296 & 3.556 & 4.73 & 2.905 & -1.142 \\
\hline \multirow[t]{3}{*}{ Winnipeg SW } & 4.204 & 3.265 & 4.64 & 2.735 & -1.312 \\
\hline & \multicolumn{5}{|l|}{ Northern PSAs } \\
\hline & $\begin{array}{l}\text { Population } \\
\text { weighted per } \\
\text { capita allocation }\end{array}$ & $\begin{array}{l}\text { Population } \\
\text { unweighted per } \\
\text { capita allocation }\end{array}$ & $\begin{array}{l}\text { Observed } \\
\text { crude } \\
\text { visits/capita }\end{array}$ & $\begin{array}{l}\text { Premature } \\
\text { mortality } \\
(0-74 y)\end{array}$ & $\begin{array}{l}\text { SERI } \\
\text { scores }\end{array}$ \\
\hline Oxford House & 6.893 & 9.782 & 10.51 & 4.841 & 3.767 \\
\hline Island Lake & 6.646 & 9.145 & 10.74 & 3.907 & 3.389 \\
\hline Norway Cross & 6.470 & 8.744 & 7.33 & 5.229 & 2.758 \\
\hline Leaf Rapids & 4.896 & 5.462 & 3.92 & 4.038 & 0.406 \\
\hline The Pas & 5.095 & 5.710 & 4.55 & 5.459 & 0.284 \\
\hline Thompson & 4.902 & 5.385 & 5.76 & 4.863 & 0.251 \\
\hline Flin Flon & 5.169 & 5.757 & 5.25 & 4.971 & 0.132 \\
\hline Gillam & 4.546 & 4.595 & 5.67 & 5.063 & -0.328 \\
\hline Churchill & 4.603 & 4.667 & 1.07 & 5.252 & -0.336 \\
\hline
\end{tabular}

true of all the Northern areas. A population weighted allocation gives all Northern regions lower per capita entitlements than does the unweighted analysis and the differences seem to be larger the worse off the population of the PSA. In the worst off areas of Island Lake, Oxford House and Norway Cross the differences are very great indeed: in the order of two visits per capita.

These differences in allocations under weighted and unweighted analyses can be seen directly by computing the differences in entitlements (weighted analysis minus unweighted analysis) for each PSA and graphing it, again, in order of increasing SERI. Figure 3 presents that picture. Here the normative implications of choosing between the two estimations are clear. The five best off and more populous PSAs show a positive gain if weighted analysis is opted for over an unweighted analysis while the rest of the PSAs lose visits under that choice. And the worse off the PSA in terms of SERI, the more they lose. The relation is a

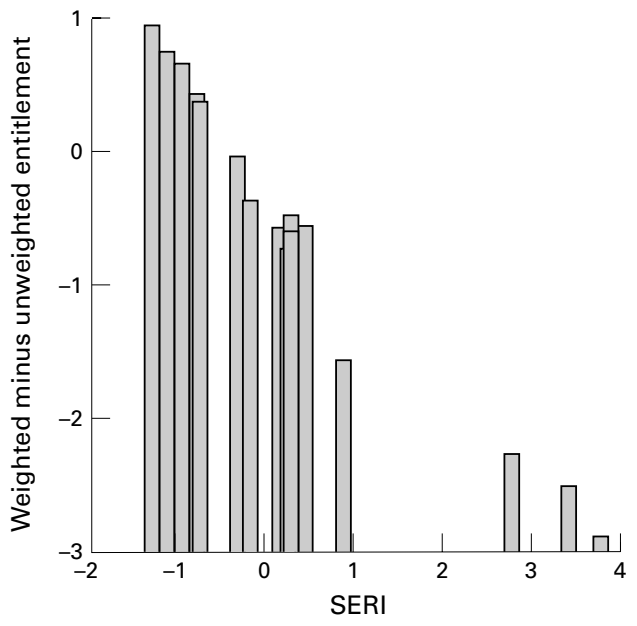

Figure 3 Differences in entitlement. very strong one. One can look at differences in entitlements between the weighted and unweighted estimates as they relate to the SERI of the PSA. A linear regression model estimating that relation is significant at the 0.001 level and explains over $95 \%$ of the variance.

\section{Discussion}

The differences noted above offer evidence of very different treatments of PSAs under the two analyses. The spread between the entitlements of the best and worst off PSAs is greater in the weighted as compared with the unweighted analysis. In the weighted analysis the range is $(6.89-4.20)$ or 2.69 visits per capita while in the unweighted analysis it is (9.783.26) or 6.52 visits per capita.

The data reveal that the weighted analysis decreases the entitlements (from observed actual rates) of the better off Winnipeg areas only marginally (between 0.05 and 0.6 visits per capita), but it also decreases the entitlements of the poorer urban areas as well $(0.02$ to $0.5)$. In the North, it decreases the per capita entitlements of all save three of the Northern areas by even wider margins. By contrast the unweighted analysis reduces the entitlements of many of the better off Winnipeg areas quite substantially while increasing the entitlements of two of the three worse off Winnipeg areas. In the Northern areas the unweighted analysis increases the entitlements of two more areas than does the weighted analysis, but where reductions occur, they are generally much less severe.

So the general effect of an unweighted analysis is to smooth the entitlements in accordance with expectations and to favour the worse off areas more strongly.

Unweighted analysis shifts considerably more resources to the worse off areas. Which is the more appropriate allocation?

There is a straightforward argument that can be made in favour of the unweighted analysis in this case. Universal access to primary care visits can be assumed to be somewhat responsive to underlying need. There should be some rough but imperfect correspondence between the use of visits and measures of health status and/or other measures of need. A few disturbing factors might mitigate against a better fit between need and utilisation. One is the availability of physicians (both supply level and in terms of proximity), another is the availability of information regarding access to the system. Any calculation of entitlement should be expected to correct for disturbing factors and to reallocate per/capita entitlements away from the less needy towards the more needy areas. It should be expected to increase the variance between the worst off and best off areas in favour of the former. Of course, question of the appropriate coefficient for needs adjustment has bedevilled needs based planners. Exactly how many additional health care resources ought to be allocated to areas per unit increment in the measure (either premature mortality or SERI) is an issue that remains open but our analysis does allow us to draw some general conclusions. 
Conclusions: To weight or not to weight A purely theoretical argument can be made for the use of an analysis unweighted by population in a number of cases. When one performs an analysis weighted by population, then the population size of each area enters into the equation as a factor determining entitlement to health care resources. We know of no studies that indicate that the size the population of a community, in itself, affects the health status and need for health care services of the population. Hence, it is not appropriate to weight analyses by the population. However, as a referee has noted, other factors, highly correlated with population size, such as supply of services, or travel distance to access service, may affect utilisation. In those cases, care should be taken to identify any variables which are candidates to affect entitlement and they should be included in the model. If there is a suspicion that some variables, such as supply factors, are not measurable but are highly correlated with population size, then population size might be used, but only as a self standing variable. It should not enter as a weight to modify and mask other effects.

It should also be noted that in estimating entitlement on the basis of socioeconomic and demographic variables (and their interactions) we are allowing that the variables in question may interact in the different PSAs in different ways. To be more concrete, in the worse off areas (socioeconomically) the pattern of utilisation of care may be different across the age/gender strata than it is in the better off PSAs. Hypothesise, for the sake of example, that there are more visits in early childhood and young adulthood per capita in the poorer PSAs and fewer in very old age. If the poorer PSAs are much less populous in the province, then a weighted analysis would impose on them the utilisation pattern of the better off, more populous, PSAs. An unweighted analysis allows for each unit to represent a pattern of utilisation across the variables in question and to provide coefficients for utilisation across PSAs as the units of analysis. An unweighted analysis treats utilisation as a community (or PSA) level phenomenon. The SERI is not an individual measure but a measure that characterises background conditions in an area. Hence, the appropriate unit of analysis is not the individual, but the area. Another general conclusion is, therefore, that, weighting by population is not appropriate in such cases.

There are, however, two important caveats to this argument. An unweighted analysis is subject to fluctuation (and hence manipulation) as a function of the way in which areas are defined. It is important that the areas chosen for analysis have some claim to theoretical relevance for the issue in question, and not be chosen arbitrarily. Moreover, assigning each community equal weight allows very small communities the same impact on the definition of average utilisation patterns as very large communities.

Nevertheless, the burden of the previous arguments lead us to conclude that population size should not be used as a weighting variable in an analysis when area effects are anticipated. In the example we have used, and by implication in all cases that share its characteristics, we have shown that the decision to weight or not can have major implications for the estimate obtained: its accuracy and its normative impact. The question of weighting by population in estimating relations, then, is a substantive and normative issue that needs careful consideration.

The authors would like to thank Noralou Roos, David Friesen and Leonard MacWilliam for their help in the initial project whence this argument sprung. We would also like to thank the community within the Manitoba Centre for Health Policy and Evaluation for innumerable and unspecifiable suggestions over numerous drafts of this argument. Three anonymous referees have also made a number of helpful suggestions. Funding: support for the research was provided by the Centre. K C Carriere was funded in part by Natural Sciences and Engineering Research Council of Canada, Alberta Heritage Foundation for Medical Research and National Health Research and Development Program. L Potvin is funded by the Medical Research Council of Canada through a Scientist Career Award (MRC H3-17299-AP007270).

Conflicts of interest: none.

1 Roos NP, Fransoo R, Bogdanovic B, et al. Needs-based planning for Manitoba's generalist physicians. A volume in the Population Health Information System issued by the Manitoba Centre for Health Policy and Evaluation. Winnipeg: Manitoba, 1996.

2 Rothman KJ. Modern epidemiolgy. Boston: Little, Brown, 1986.

3 Mustard C, Derksen S. A needs-based funding methodology for Regional Health Authorities: a proposed framework. A volume in the Population Health Information System issued by the Manitoba Centre for Health Policy and Evaluation. Winnipeg: Manitoba, 1998

4 Kawachi I, Berkman L. Social cohesion, social capital, and health. In: Berkman LF, Kawachi I, eds. Social epidemiology health. In: Berkman LF, Kawachi I, eds. Social epiden

5 Kennedy BP, Kawachi I, Prothrow-Smith D. Income distribution and mortality: cross-sectional ecological study of the Robin Hood Index in the United States. BMF 1996;312:1004-7

6 Kaplan GA, Pamuk ER, Lynch JW, et al. Inequality in income and mortality in the United States: Analysis of mortality and potential pathways. BMF 1996;312:9991003

7 Korn EL, Graubard BI. Examples of differing weighted and unweighted estimates from a sample survey. AmerStat 1995;49:291-5

8 Klockars AJ, Hancock GR, McAweeney MJ. Power of unweighted and weighted versions of simultaneous and sequential multiple-comparison procedures. Psychol Bull 1995;118:300-7.

9 Cornell JA.Weighted versus unweighted estimates using Scheffle's mixture model for symmetrical error variance Scheffle's mixture model for symm
patterns. Technmcs 1977;19:237-47.

10 Morgenstern H. Ecological studies in epidemiology: concepts, principles and methods. Annu Rev Public Health 1995;16:61-81

11 Morgenstern $\mathrm{H}$. Uses of ecologic analysis in epidemiologic research. Am $\mathcal{F}$ Public Health 1982;72:1336-44.

2 Greenland S, Robins J. Invited commentary: Ecologic studies-biases, misconceptions, and counterexamples. Am 7 Epidemiol 1994;139:747-60

13 Shy CM. The failure of academic epidemiology: Witness for the prosecution. Am $\mathcal{F}$ Epidemiol 1997;145:479-84.

14 Frohlich KL, Potvin L. Health promotion through the lens of population health: toward a salutogenic setting. Critical Public Health 1999;9:211-22.

15 Krieger N, Williams D, Moss N. Measuring social class in US public health research: concepts, methodologies, and
guidelines. Ann Rev Public Health 1997; 18:341-78.

16 Bryk AS, Radenbush, SW. Hierarchical linear models: applications and data analysis methods. Newbury Park, CA: Sage, 1992.

17 Ross NA, Wolfson, MJ, Duncan, JR, et al. Relations between income inequality and mortality in Canada and in the United States: cross sectional assessment using census data and vital statistics. BMF 2000;320:898-902.

18 Campbell DT. Common fate, similarity, and other indices of the status of aggregates of persons as social entities. Behav Sci 1958;3:14-25.

19 Firebaugh G. Groups as contexts and frog ponds. In: Roberts $\mathrm{KH}$, Burstein L, eds. Issues in aggregation. New Directions for Methodology of Social and Behavioral Science, no 6. San Francisco: Jossey Bass 1980:43-52.

20 Cheaddle A, Wagner E, Koepsell T, et al. Environmental indicators: a tool for evaluating community-based health-promotion programs. Am f Prev Med 1992;8:34550.

21 Von Korff M, Koepsell T, Curry S, et al. Multi-level analysis in epidemiologic research on health behaviors and outcomes. Am Ұ Epidemiol 1992;135:1077-82. 
22 Birch S, Eyles J, Hurley J, et al. A needs-based approach to resource allocation in health care. Can Public Policy resource allocation

23 Eyles J, Birch S, Chambers S, et al. A needs-based methodology for allocating health care resources in Ontario, Canada: development and an application. Soc Sci Med 1991;33: 489-500.

24 Frohlich N, Carriere KC. Issues in needs based funding. A volume in the Population Health Information System issued by the Manitoba Centre for Health Policy and Evaluation,

25 Wrohlich N, Mustard C. Socio-economic characteristics. A volume in the Population Health Information System issued by the Manitoba Centre for Health Policy and Evaluation. Winnipeg: Manitoba, 1994

26 Frohlich N, Mustard C. A regional comparison of socio-economic and health indices in a Canadian province. Soc Sci Med 1996;42:1273-81.

\section{Want full access but don't have a subscription?}

\section{Pay per access}

For just US\$25 you can have instant access to the whole website for 30 days. During this time you will be able to access the full text for all issues (including supplements) available. You will also be able to download and print any relevant pdf files for personal use, and take advantage of all the special features Journal of Epidemiology and Community Health online has to offer.

www.jech.com 